\section{AB1366-HPR THE EFFECTS OF LAND AND WATER BASED MULTIDIMENSIONAL FUNCTIONAL MOBILITY EXERCISES ON PULMONARY FUNCTIONS IN ANKYLOSING SPONDYLITIS PATIENTS}

Baris Gurpinar ${ }^{1}$, Nursen Ilcin ${ }^{1}$, Sema Savci ${ }^{1}$, Nurullah Akkoc ${ }^{2} .{ }^{1}$ Dokuz Eylul University, izmir, Turkey; ${ }^{2} x x x x x x$, Izmir, Turkey

Background: Pulmonary manifestations are common in ankylosing spondylitis (AS) yet there is not enough evidence about the results of different interventions on pulmonary functions.

Objectives: The aim of this study was to evaluate the pulmonary effects of land and water based multidimensional functional mobility exercises on pulmonary functions in AS patients.

Methods: This is a single-blinded, randomized and experimental study conducted in outpatient clinic and thermal center. A total of 38 patients with definite ankylosing spondylitis according to the modified New York criteria were recruited for the study Patients were randomly allocated to aquatic (AG) and land (LG) exercise group twice in a week for 8 weeks. Pulmonary Function Tests (PFT), maximal inspiratory mouth pressure (MIP), and maximal expiratory mouth pressure (MEP) were measured before and after the intervention.

Results: 3 patients from $A G$ and 6 from LG missed 4 sessions consecutively. In AG, PEF $(p=0.004)$, VC $(p=0.025)$, MVV $(p=0.006)$ and MIP $(p=0.001)$ improved significantly on the other hand in LG FEV1/FVC (0.049), PEF $(p=0.007)$ and MVV $(p=0.004)$ significantly increased.

Conclusion: Performing multidimensional functional mobility exercises in water and on land could have different results. Exercising in water could have additional benefits such as increasing inspiratory muscle strength.

\section{REFERENCES}

[1] Berdal G, Halvorsen S, van der Heijde D, Mowe M, Dagfinrud H. Restrictive pulmonary function is more prevalent in patients with ankylosing spondylitis than in matched population controls and is associated with impaired spinal mobility: a comparative study. Arthritis research \& therapy. 2012;14 (1):R19.

[2] Gyurcsik ZN, András A, Bodnár N, Szekanecz Z, Szántó S. Improvement in pain intensity, spine stiffness, and mobility during a controlled individualized physiotherapy program in ankylosing spondylitis. Rheumatology International. 2012;32(12):3931-6.

[3] Altan L, Bingöl Ü, Aslan M, Yurtkuran M. The effect of balneotherapy on patients with ankylosing spondylitis. Scandinavian Journal of Rheumatology. 2006 2006/01/01;35(4):283-9.

[4] van Tubergen A, Hidding A. Spa and exercise treatment in ankylosing spondylitis: fact or fancy? Best Practice \& Research Clinical Rheumatology. 2002 2002/09/01;16(4):653-66.

[5] Seckin U, Bolukbasi N, Gursel G, Eroz S, Sepici V, Ekim N. Relationship between pulmonary function and exercise tolerance in patients with ankylosing spondylitis. Clinical and experimental rheumatology. 2000;18(4):5036.

Disclosure of Interests: None declared

DOI: 10.1136/annrheumdis-2019-eular.7940

\section{AB1367-HPR EFFECTIVENESS OF THE HYPERBARIC TREATMENT ON THE PERCEIVED PAIN, FATIGUE AND FUNCTIONALITY OF WOMEN WITH FIBROMYALGIA}

Ruth Izquierdo Alventosa ${ }^{1}$, Marta Inglés ${ }^{2}$, Sara Cartés Amador ${ }^{2}$ Lucía Gimeno-Mallench ${ }^{3}$, Àngels Vidal ${ }^{3}$, Javier Chirivella ${ }^{1}$, Juri D. Kropotov ${ }^{4}$ Pilar Serra Añó2. ${ }^{1}$ Fundación FIVAN, Valencia, Spain; ${ }^{2}$ University of Valencia, Physiotherapy, Valencia, Spain; ${ }^{3}$ University of Valencia, Physiology, Valencia, Spain; ${ }^{4}$ N. P. Bechtereva Institute of the Human Brain, Russian Academy of Sciences, St Petersburg, Russian Federation

Background: Fibromyalgia (FM) is a chronic pain syndrome accompanied by other symptoms such as fatigue or altered functionality ${ }^{1}$. One of the most common non-pharmacologic treatment is physical exercise because of its known positive influence on pain as a consequence of the physical condition improvement. ${ }^{2}$ However, they use to present a lack of adherence to this type of therapeutic programs may be attributable to postexercise pain ${ }^{3}$. For this reason, alternative approaches that do not involve physical efforts, such as hyperbaric therapy, may be effective to reduce pain, fatigue or functionality in women with $\mathrm{FM}^{4}$

Objectives: To compare the effectiveness of hyperbaric therapy and physical exercise on pain, fatigue and functionality in women with FM.

Methods: A randomized control trial was conducted. 28 women with FM were divided in two intervention groups: One group, composed of 14 women, received a low-intensity physical exercise program twice a week for 8 weeks (PEG). The other group received 40 sessions of hyperbaric treatment, 5 times per week (HBTG). To determine the effect of these therapeutic programs, the perceived pain was assessed with an analogue visual scale. Further, the fatigue was measured with the Borg scale and the covered walked distance with The Six minutes walk test. The meas urements were conducted two times, before and one week after finishing the treatment. The effect of the treatments was statistically analyzed with a mixed factorial ANOVA with the between-subject factor called 'group' (categories: PEG and HBTG) and with the within-subject factor called 'intervention' (categories: pre and post-intervention).

Results: Our study shows that hyperbaric treatment significantly improved functionality and reduced the levels of pain and fatigue (Table 1). The physical exercise intervention improved functionality, but this program could not reduce the experienced intensity of pain nor the perceived fatigue $(p>0.05)$

Abstract AB1367HPR Table 1. Effect of the physical exercise program and hyperbaric therapy on pain, fatigue and functionality.

\begin{tabular}{lccc}
\hline & & $\begin{array}{c}\text { Pre- } \\
\text { intervention }\end{array}$ & $\begin{array}{c}\text { Post- } \\
\text { intervention }\end{array}$ \\
\hline Pain & PEG & $6.21(2.29)$ & $5.57(2.24)$ \\
\hline HBTG & 7.43 & $5.07(2.50)^{\star}$ & \\
Fatigue & $(1.70)$ & $6.86(2.82)$ & $7.21(2.52)$ \\
& PEG & $7.79(2.15)$ & $6.5(2.24)^{\star}$ \\
Distance & HBTG & $489.21(76.39)$ & $516.64(71.58)^{*}$ \\
& PEG & $507.14(67.46)$ & $566.79(71.55)^{*}$ \\
\hline
\end{tabular}

Data are shown as mean (SD). PEG: physical exercise group; HBTG: hyperbaric treatment group.

Conclusion: Both hyperbaric therapy and physical exercise achieved an improvement in the functionality. Nevertheless, only the hyperbaric therapy achieved a decrease in perceived pain and an improvement in the perceived fatigue.

\section{REFERENCES}

[1] Wolfe F, Clauw DJ, Fitzcharles M-A, Goldenberg DL, Katz RS, Mease P, et al. The American College of Rheumatology preliminary diagnostic criteria for fibromyalgia and measurement of symptom severity. Arthritis Care Res. 2010;62(5):600-610.

[2] Ambrose KR, Golightly YM. Physical exercise as non-pharmacological treatment of chronic pain: why and when. Best Pract Res Clin Rheumatol. 2015:29(1):120-130.

[3] Dobkin PL, Sita A, Sewitch MJ. Predictors of adherence to treatment in women with fibromyalgia. Clin J Pain. 2006;22(3):286-294.

[4] Wilson HD, Wilson JR, Fuchs PN. Hyperbaric oxygen treatment decreases inflammation and mechanical hypersensitivity in an animal model of inflammatory pain. Brain Res. 2006;1098(1):126-128.

Disclosure of Interests: None declared

DOI: 10.1136/annrheumdis-2019-eular.5538

\section{AB1368-HPR ENHANCED ROLE OF NURSES AND OTHER HEALTHCARE PROFESSIONALS (HCPS) IN THE CARE OF RHEUMATOID ARTHRITIS AND ASSOCIATED COMORBIDITIES}

Alison Kent ${ }^{1}$, Cem Gabay ${ }^{2}$, Rinie Geenen ${ }^{3}$, Ioanna Gouni-Berthold ${ }^{4}$, Frank van den Hoogen $^{5}$, Lars Klareskog ${ }^{6}$, Mikkel Ǿstergaard ${ }^{7}$, Karel Pavelka ${ }^{8}$, Joaquim Polido-Pereira ${ }^{9}$, Anne Grete Semb ${ }^{10}$, Magnus Sköld ${ }^{6}$, Alejandro Balsa ${ }^{11}$, Neil Betteridge ${ }^{12}$, Maya Buch ${ }^{13}$, Maxime Dougados ${ }^{14}$, Patrick Durez ${ }^{15}$ Ennio Favalli ${ }^{16}$, Guillaume Favier ${ }^{17}$, Tore K. Kvien ${ }^{10}{ }^{1}$ Salisbury NHS Foundation Trust Hosp, Salisbury, United Kingdom; ${ }^{2}$ Geneva Hosp, Geneva, Switzerland; ${ }^{3}$ Utrecht U, Utrecht, Netherlands: ${ }^{4}$ Polyclinic for Endo, Diab and Prev Med, U Cologne, Cologne, Germany, ${ }^{5}$ Sint Maartenskliniek, Nijmegen, Netherlands; ${ }^{6}$ Karolinska Inst and Karolinska U Hosp, Stockholm, Sweden; ${ }^{7}$ Rigshospitalet, Copenhagen, Denmark; ${ }^{8}$ Inst Rheumatology, Prague, Czech Republic; ${ }^{9}$ Hosp Santa Maria, Lisbon, Portugal; ${ }^{10}$ Diakonhjemmet Hosp, Oslo, Norway; ${ }^{11} \mathrm{Hosp} U$ La Paz, Madrid, Spain; ${ }^{12}$ Betteridge Associates, London, United Kingdom; ${ }^{13} \mathrm{Chapel}$ Allerton Hosp, Leeds, United Kingdom; ${ }^{14}$ Cochin Hosp, Paris, France; ${ }^{15} \mathrm{Clin} U$ Saint-Luc, IREC, Brussels, Belgium; ${ }^{16}$ Gaetano Pini Inst, Milan, Italy, ${ }^{17}$ KPMG LLP, London, United Kingdom

Background: Long-term morbidity and mortality in patients with rheumatoid arthritis (RA) are increased $^{(1)}$ due to the increased risk of comorbidities 